\title{
Inhibitors of oestrogen biosynthesis: preclinical studies with CGS 16949A, a new nonsteroidal aromatase inhibitor
}

\author{
Ajay S. Bhatnagar, Klaus Schieweck and Albert Häusler \\ Research Department, Pharmaceuticals Division, CIBA-GEIGY Limited, \\ 4002 Basel, Switzerland \\ and \\ Leslie J. Browne and Ronald E. Steele \\ Research Department, Pharmaceuticals Division, CIBA-GEIGY Corporation, \\ Summit, NJ 07901, U.S.A.
}

\begin{abstract}
Synopsis
Inhibitors of the aromatase enzyme represent a class of therapeutic agents which potently inhibit oestrogen biosynthesis in vivo. This inhibition of oestrogen biosynthesis is well established as effective therapy in the treatment of oestrogen-dependent breast cancer. CGS 16949A [4-(5,6,7,8-tetrahydroimidazo-[1,5-a]pyridin-5-yl)-benzonitrile hydrochloride] is a non-steroidal imidazole derivative which is a potent competitive aromatase inhibitor in vitro. At a maximally effective concentration, it selectively inhibits aromatase and does not affect glucocorticoid production from the adrenal in vitro.

In vivo in the rat, CGS $16949 \mathrm{~A}$ effectively reduces ovarian oestrogen content and potently inhibits an aromatase-mediated androgen-induced uterine hypertrophy. Oral treatment of adult, cyclic female rats with CGS 16949A disrupts cyclicity, inhibits ovulation, reduces uterine weight and suppresses serum oestradiol, all expected sequelae of oestrogen deprivation. At maximally effective doses, there is no evidence of adrenal hypertrophy, indicating that adrenal steroidogenesis is unaffected. In the DMBAinduced mammary carcinoma model in the rat, CGS 16949A caused almost complete regression of palpable tumours and significantly suppressed the appearance of new tumours at a maximally effective oral dose. Thus, CGS $16949 \mathrm{~A}$ is a potent and selective inhibitor of the aromatase enzyme. In the rat, it is very efficacious in inhibiting oestrogen biosynthesis and in suppressing the growth of DMBA-induced mammary tumours.
\end{abstract}

\section{Introduction}

In the overall scheme of mammalian steroidogenesis, aromatase is the enzyme complex which effects the last step in the biosynthesis of oestrogens from the steroidal precursor cholesterol (Fig. 1). In the female, aromatase is located most importantly in the ovary, adipose tissue, breast, brain and liver. In the adult premenopausal woman, the ovary is the predominant source of circulating oestrogens and thus is the tissue with the highest amount of aromatase. In the postmenopausal woman, the major source of circulating oestrogens has been shown to be from the conversion of adrenal androgens to oestrogens by aromatase in peripheral tissues like adipose tissue including the breast (Grodin et al. 1973). Thus aromatase is a key enzyme in the biosynthesis of oestrogens both in premenopausal and postmenopausal women.

Inhibition of the enzymatic activity of aromatase leads to a reduction in oestrogen biosynthesis. In the premenopausal woman, this reduction in ovarian biosynthesis can be overcome by a compensatory increase in circulating gonadotrophins resulting from a functional feedback system. In the postmenopausal woman, however, extraovarian oestrogen biosynthesis is not under feedback control, thus reductions in 


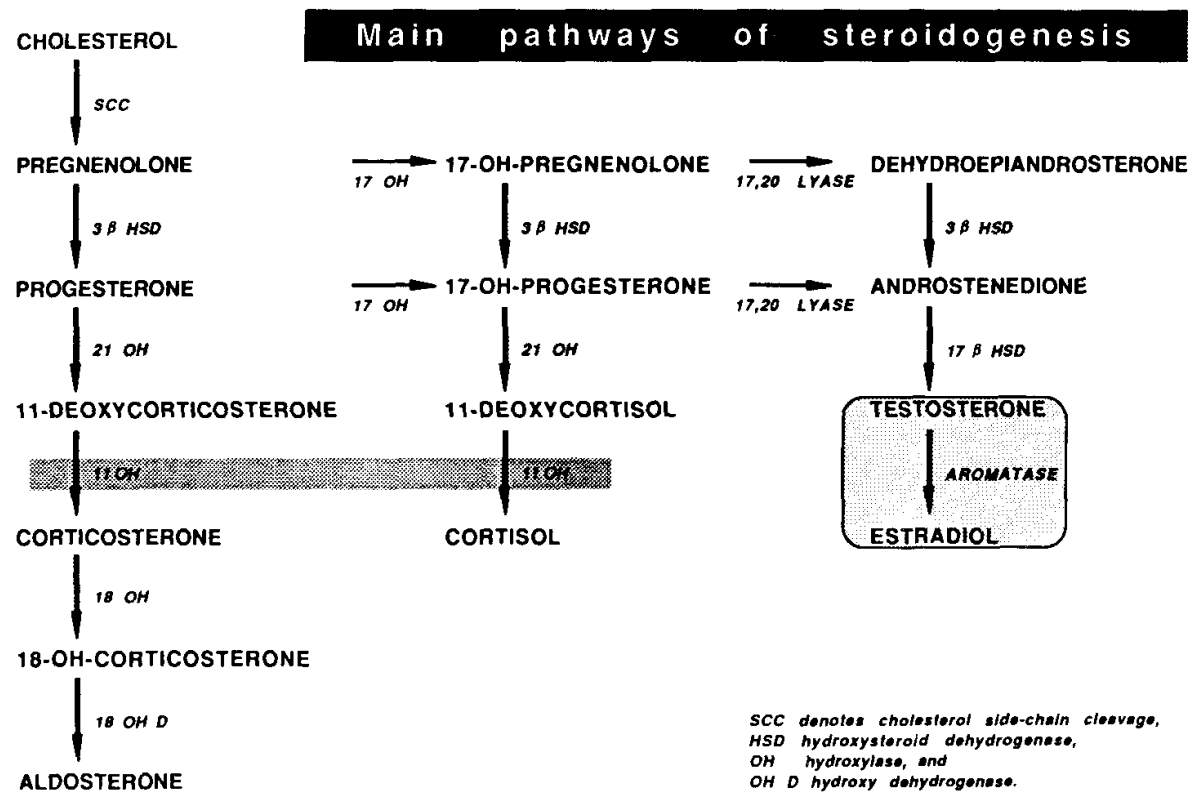

Figure 1. A composite of the main pathways of mammalian steroidogenesis.

circulating oestrogens can be maintained through the inhibition of aromatase.

Like several other steroidogenic enzymes, aromatase is a cytochrome P-450 dependent enzyme. Some inhibitors of aromatase are compounds which bind and thus inhibit this component of the aromatase enzyme system, making them potential inhibitors of other steroidogenic enzymes.

Since inhibition of aromatase could be a highly effective way of reducing the concentrations of circulating oestrogens, it would also be effective therapy in the treatment of oestrogen-dependent disease, the most important of which is oestrogendependent breast cancer. Thus the past two decades have seen the synthesis and development of pharmacological agents which potently inhibit aromatase in a highly selective way.

\section{Chemistry of aromatase inhibitors}

Inhibitors of the aromatase enzyme are basically of two chemical types. They are either derivatives of steroids which act as competitive inhibitors of the natural aromatase enzyme substrate androstenedione, or they are non-steroidal in nature and may bind, in addition, to the cytochrome P-450 of the aromatase enzyme complex. Aminoglutethimide (a non-steroidal compound) and testolactone (a steroidal compound) were first identified as being inhibitors of aromatase in the mid $1970 \mathrm{~s}$ (Thompson \& Siiteri 1974; Siiteri \& Thompson 1975, respectively). They had been developed, however, as an inhibitor of adrenal steroidogenesis and an androgen antagonist, respectively, and were already in use as therapeutic agents in the treatment of metastatic breast cancer, although it was not until much later that their aromatase-inhibiting properties were identified. Since then there has been a large 
number of compounds synthetised based on the structure of aminoglutethimide (Daly et al. 1986; Hartmann \& Batzl 1986) and also a large number of steroidal compounds (Johnston \& Metcalf 1984; Henderson et al. 1986) which have been synthetised as aromatase inhibitors. The first studies of steroidal compounds structurally designed to be aromatase inhibitors were reported by Schwarzel et al. 1973. These were followed by two reports characterising 4-hydroxy-androstenedione as a potent aromatase inhibitor (Brodie et al. 1976; Brodie et al. 1977). Very recently, a new imidazole derivative, CGS 16949A, has been synthetised which shows extremely high potency as an aromatase inhibitor (Browne et al. 1986; Steele et al. 1987). The chemical structures of four of these compounds are shown in Figure 2. Our efforts were directed to the synthesis of non-steroidal aromatase inhibitors which, among other criteria, were potent, selective and efficacious in their inhibition of the aromatase enzyme.

\section{Potency and selectivity in vitro}

Potency of aromatase inhibitors is usually assessed in an in vitro system using human placenta as the source of the aromatase enzyme and then measuring the inhibition of the aromatisation of the natural substrate androstenedione to the oestrogen oestrone. This aromatisation reaction can either be followed by measuring the amount of tritiated water released when a tritiated substrate, $1 \beta, 2 \beta-{ }^{3} \mathrm{H}$-androstenedione, is aromatised to oestrone, as reported by Thompson \& Siiteri 1974, or by isolating the ${ }^{14} \mathrm{C}$-labelled oestrogens which result when ${ }^{14} \mathrm{C}$-androstenedione is aromatised. Using the latter product isolation method, compounds were assessed for their ability to inhibit aromatase. The results are expressed as the concentrations at which they inhibited the conversion of androstenedione to oestrogens by $50 \%\left(\mathrm{IC}_{50}\right)$ and as the<smiles>CC1(c2ccc(N)cc2)CCC(=O)NC1=O</smiles>

Aminoglutethimide<smiles>CC12CCC3C(CCC4=CC(=O)C=CC43C)C1CCC(=O)O2</smiles>

Testolactone<smiles>CC12CCC3C(CCC4=C(O)C(=O)CCC43C)C1CCC2=O</smiles>

4-OH-Androstenedione

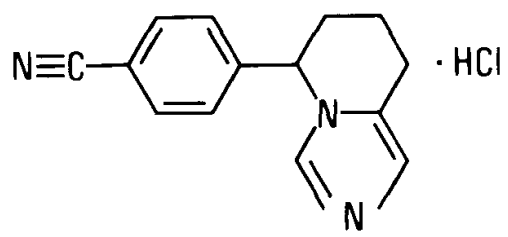

CGS 16949A

Figure 2. Chemical structures of nonsteroidal and steroidal aromatase inhibitors. 
Table 1. Inhibition of human placental aromatase.

$\begin{array}{lrc}\text { Inhibitor } & \mathrm{IC}_{50} \mathrm{nM} & \mathrm{K}_{\mathrm{i}} \mathrm{nM} \\ \text { Testolactone } & 8000 & 4600 \\ \text { Aminoglutethimide } & 1900 & 530 \\ \text { CGP 32349 } & 62 & 20 \\ \text { CGS 16949A } & 5 & 1.4\end{array}$

classic inhibition constant $\left(\mathrm{K}_{\mathrm{i}}\right)$ derived from a Lineweaver-Burk plot. The results are shown in Table 1.

Testolactone is the least potent of the four compounds with an increase in potency with aminoglutethimide, followed by 4-hydroxy-androstenedione (CGP 32349) and CGS 16949A, the last two being about 30 and 400 times as potent, respectively, as aminoglutethimide.

Aminoglutethimide, which is a potent aromatase inhibitor, also inhibits other cytochrome P-450-dependent enzymes. Before the aromatase inhibiting properties of aminoglutethimide were recognised, it was used as a pharmacological agent to effect a so-called medical adrenalectomy. Thus although aminoglutethimide is a potent inhibitor of aromatase, it was not selective in its action. We have recently reported a method which assesses the degree of selectivity of an aromatase inhibitor (Häusler $e t$ al. 1989). Briefly, in this in vitro method, steroidogenesis is stimulated by incubating hamster ovarian slices with the gonadotrophin luteinising hormone ( $\mathrm{LH})$ in either the presence or absence of the aromatase inhibitor being tested. The release of LHstimulated progesterone and oestradiol into the medium is then measured. A selective inhibitor of aromatase will inhibit the production of oestradiol without inhibiting the production of progesterone. Inhibition of adrenal steroidogenesis was also studied by measuring the inhibition of adrenocorticotrophic hormone (ACTH)-induced corticosterone production in rat adrenal fragments in vitro by the method of Saffran $\&$ Schally 1955.

Figure 3 represents results obtained with aminoglutethimide and CGS 16949A in both these systems. These results, along with those for testolactone and 4-hydroxyandrostenedione, have been reported in detail elsewhere (Häusler et al. 1989). In brief, testolactone, aminoglutethimide, 4-hydroxy-androstenedione and CGS $16949 \mathrm{~A}$ inhibit the production of oestradiol by $50 \%\left(\mathrm{IC}_{50}\right)$ at concentrations of 130 , $13,0.88$ and $0.03 \mu \mathrm{M}$, respectively. Progesterone production is inhibited at concentrations $\left(\mathrm{IC}_{50}\right.$ ) of $1000,60, \geq 330$ and $160 \mu \mathrm{M}$, respectively. Thus, not only is CGS $16949 \mathrm{~A}$ by far the most potent of the four aromatase inhibitors, it is also highly selective as it only inhibits progesterone at concentrations which are over 5000 times higher than those required for inhibiting oestradiol production. This selectivity is further corroborated from results obtained for the inhibition of ACTH-induced corticosterone production in rat adrenals which are also shown in Figure 3. Here, aminoglutethimide inhibits corticosterone production with an $\mathrm{IC}_{50}$ of $50 \mu \mathrm{M}$, which is similar to that needed for inhibiting progesterone $(60 \mu \mathrm{M})$ displaying a relative lack of selectivity. On the other hand, CGS 16949A only inhibits corticosterone production with an $\mathrm{IC}_{50}$ of $100 \mu \mathrm{M}$ which is 3000 times higher than the $\mathrm{IC}_{50}$ for inhibiting oestrogen production $(0.03 \mu \mathrm{M})$. Thus in vitro, CGS $16949 \mathrm{~A}$ is by far the most potent of the four aromatase inhibitors and also highly selective in its inhibition of aromatase. 

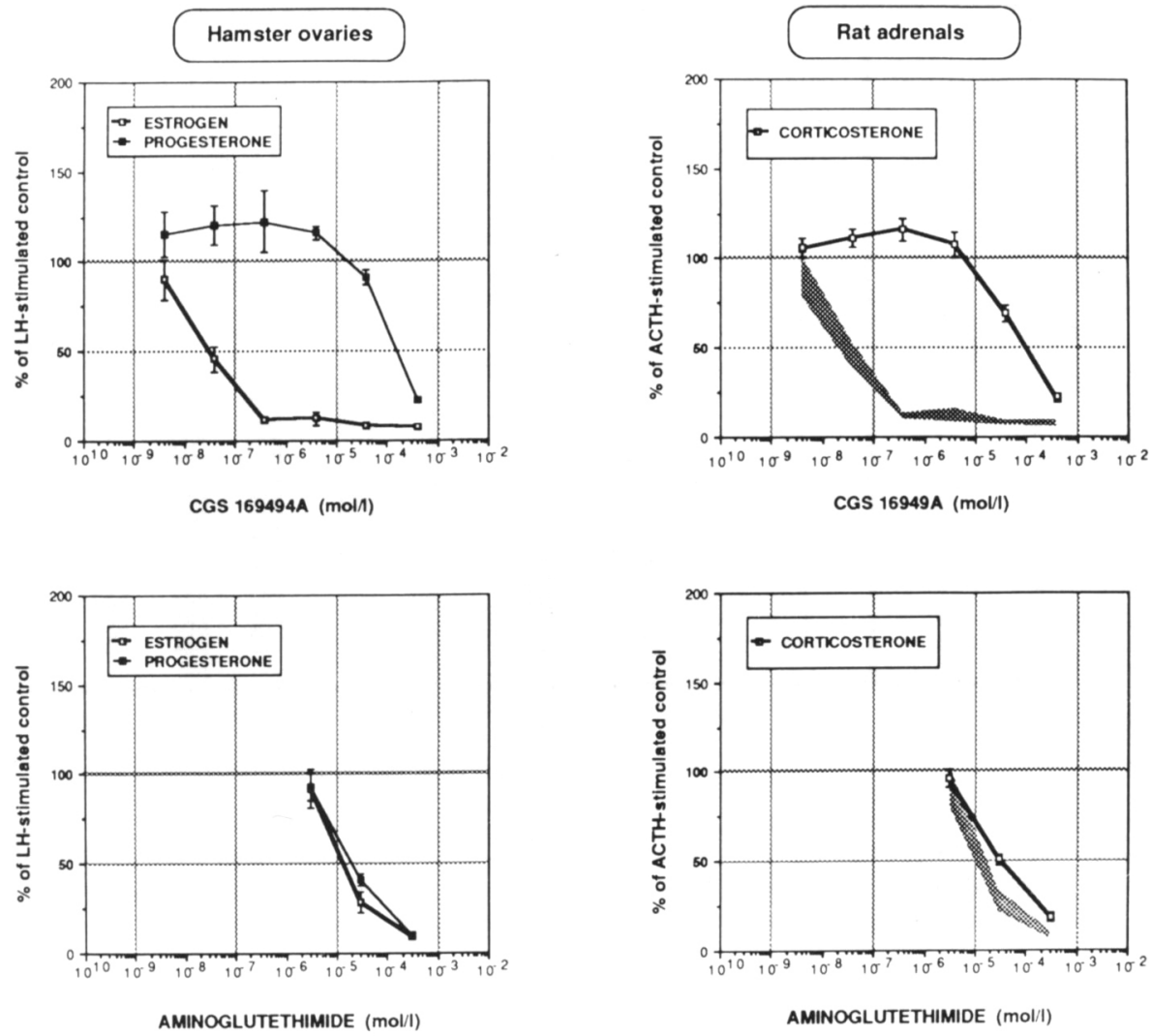

Figure 3. Inhibition in vitro of LH-stimulated oestradiol and progesterone production in hamster ovarian slices (panels to the left), and of ACTH-stimulated corticosterone production in rat adrenal fragments (panels to the right) by CGS 16949A and aminoglutethimide phosphate; shaded areas in the panels on the right represent concentrations at which oestradiol production is inhibited in hamster ovarian slices shown on the left; redrawn partly from data reported in Häusler $e t$ al. 1989.

\section{Efficacy in vivo}

\section{Inhibition of ovarian oestrogen content}

Steele et al. (1987) have recently reported that CGS 16949A maximally inhibits rat ovarian oestrogen synthesis at an oral dose of $0.26 \mathrm{mg} / \mathrm{kg}$. In the same model, aminoglutethimide produces a similar effect at an oral dose of $100 \mathrm{mg} / \mathrm{kg}$. The minimum effective dose of CGS 16949A required to elicit this inhibition of oestrogen synthesis was $0.003 \mathrm{mg} / \mathrm{kg}$. In this model, CGS $16949 \mathrm{~A}$ is about 400 times as efficacious as aminoglutethimide.

\section{Inhibition of aromatase-mediated androgen-induced uterine hypertrophy}

Knudsen \& Mahesh (1975) had shown that a variety of androgens elicited a uterotrophic effect in immature female rats. They were able to show that this oestrogen-like effect was mediated by aromatase in the immature female rat ovary and could be antagonised by ovariectomy. We reasoned that, like ovariectomy, 


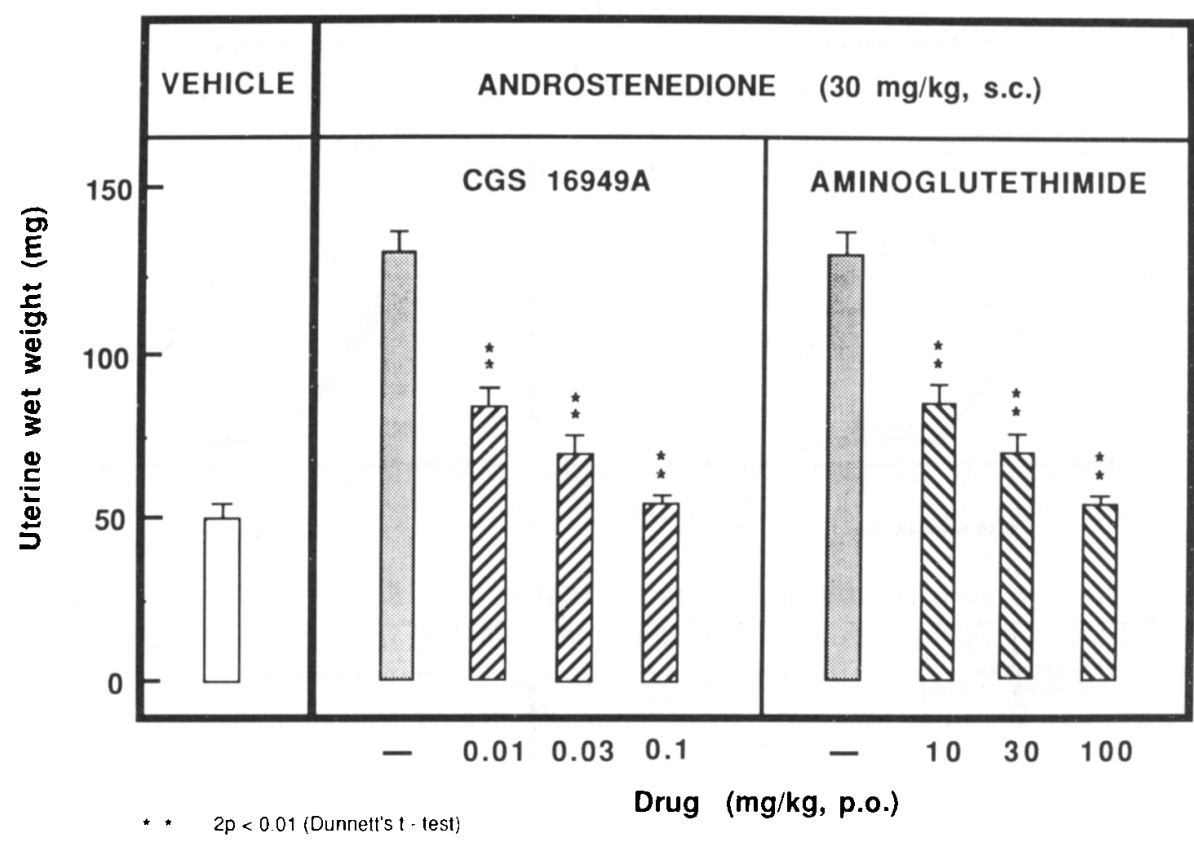

Figure 4. Effects of CGS $16949 \mathrm{~A}$ and aminoglutethimide phosphate administered p.o. concomitantly with androstenedione $(30 \mathrm{mg} / \mathrm{kg}$ s.c.), once daily for four days to immature female rats, on uterine wet weight (mean $\pm \mathrm{SEM}, \mathrm{N}=5$ for each treatment group).

aromatase inhibitors should also be able to antagonise these effects. Immature female rats were treated with androstenedione $(30 \mathrm{mg} / \mathrm{kg} \mathrm{s.c.)}$ for four days in the absence or presence of varying oral doses of either aminoglutethimide or CGS 16949A. The results are shown in Figure 4. Both aromatase inhibitors cause a dose-dependent antagonism of the induced uterine hypertrophy. In this model CGS 16949A is about 1000 times as potent as aminoglutethimide.

\section{Effects of a fourteen-day treatment with CGS 16949A in adult cyclic female rats}

CGS 16949A was administered orally, once daily at doses of $0.1,0.3$ and $3.0 \mathrm{mg} / \mathrm{kg}$ for fourteen days. Four hours after the last dose on the fourteenth day, the animals were killed and trunk blood taken for measurement of serum oestradiol, luteinising hormone and prolactin by specific radioimmunoassays. The uterus, ovaries, pituitary, adrenals, thyroid and liver were removed and weighed. During the course of the fourteen-day adminstration schedule, daily vaginal smears were taken.

Results of the vaginal cytology (data not shown) indicated that there was a doserelated disruption in ovarian cyclicity in the treated animals. All the animals in the highest dose group showed diestrus smears after the fourth day of treatment. The changes in organ weights are shown in Figure 5. There is a dose-dependent suppression of both uterine and pituitary weights which assumes statistical significance at the highest dose. Ovarian weights are significantly but not dose-dependently increased. There was no effect on adrenal, thyroid or liver weights. Serum hormone concentrations shown in Figure 6 demonstrate a significant decrease in serum 


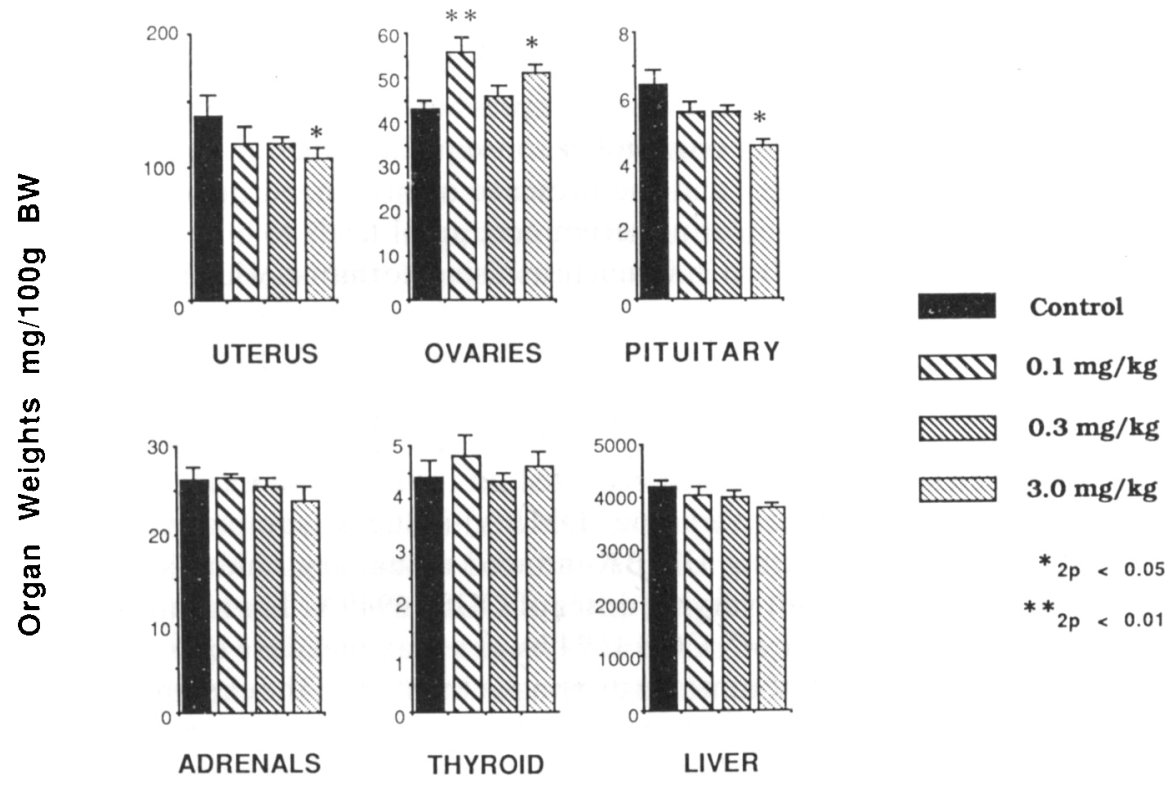

Figure 5. Effect of a once-daily fourteen-day oral treatment with CGS $16949 \mathrm{~A}$ on relative organ weights in adult female rats; results are expressed as mean $\pm \operatorname{SEM}(\mathrm{N}=8$ for each treatment group).
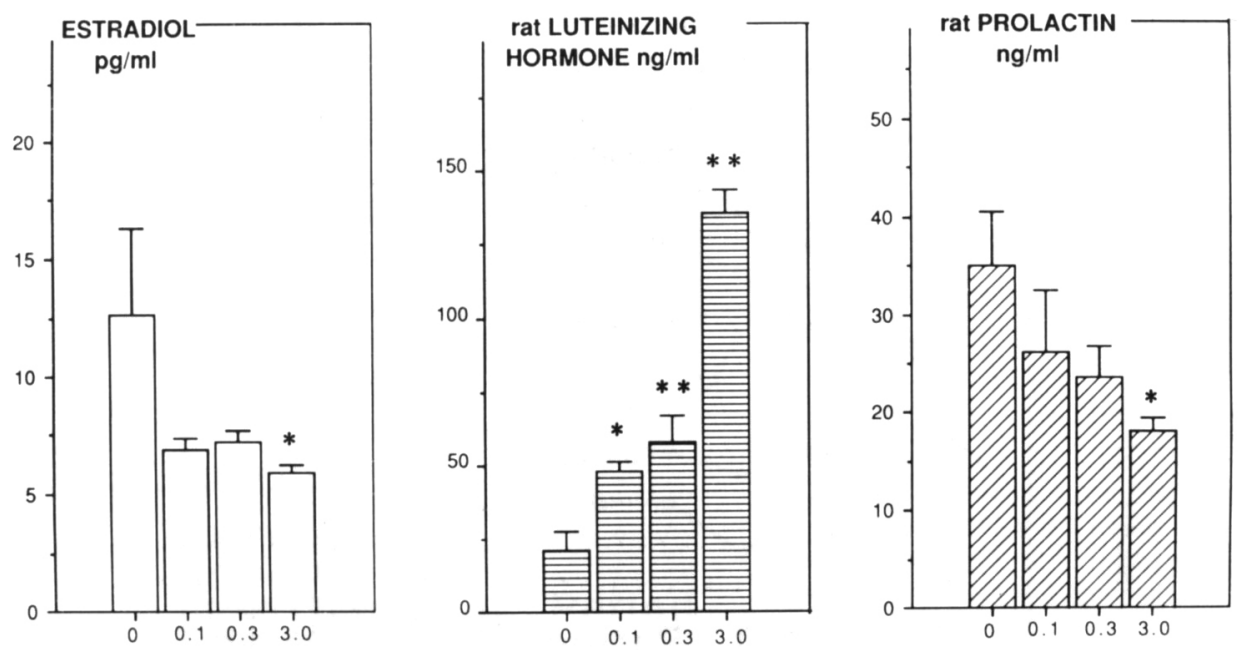

\section{CGS 16949A mg/kg p.o. $\quad \begin{array}{r}* 2 p<0.05 \\ * * 2 p<0.01\end{array}$}

Figure 6. Serum hormone concentrations in adult female rats at the end of a fourteen-day oral treatment with CGS 16949A; results are expressed as mean \pm SEM for each hormone; rat luteinising hormone and rat prolactin are expressed in terms of the reference standards NIAMD-rLH-RP1 and NIAMD-rat prolactin-RP-1, respectively; these standards and the accompanying RIA reagents were generously supplied by the NIAMD/NIH, USA. 
oestradiol and prolactin at the highest dose and a dose-dependent increase in serum luteinising hormone.

Thus CGS 16949A exhibits potent oestrogen-lowering effects in a dose-dependent manner in adult cyclic female rats. This suppression of oestrogen is-manifest by a significant reduction in serum oestradiol, a consequent reduction in uterine weight, disruption of ovarian cyclicity and the presence of prolonged periods of diestrus. Further, the reduction in circulating serum oestradiol leads to a decrease in serum prolactin and a distinct elevation in serum luteinising hormone, which in turn leads to an increase in ovarian weight.

\section{Anti-tumour efficacy in vivo}

Schieweck et al. (1988) have recently reported on the effects of CGS 16949A on the growth of the dimethylbenzanthracene (DMBA)-induced mammary carcinoma in adult female rats. Rats bearing DMBA-induced mammary tumours were treated orally for forty-two days with varying doses of CGS 16949A. The results of one such treatment are shown in Figure 7. CGS 16949A at a maximal dose of $1 \mathrm{mg} / \mathrm{kg}$ caused almost complete regression of tumours existing at the start of the experiment and also significantly suppressed the appearance of new tumours during the course of the experiment. The tumour-regressing effects were dose-dependent with a $50 \%$ effective dose $\left(E_{50}\right)$ of about $0.1 \mathrm{mg} / \mathrm{kg}$. Under the same experimental conditions, aminoglutethimide at its maximal tolerated dose of $100 \mathrm{mg} / \mathrm{kg}$ was only marginally effective.

This marked anti-tumour effect of CGS 16949A in the DMBA model led us to

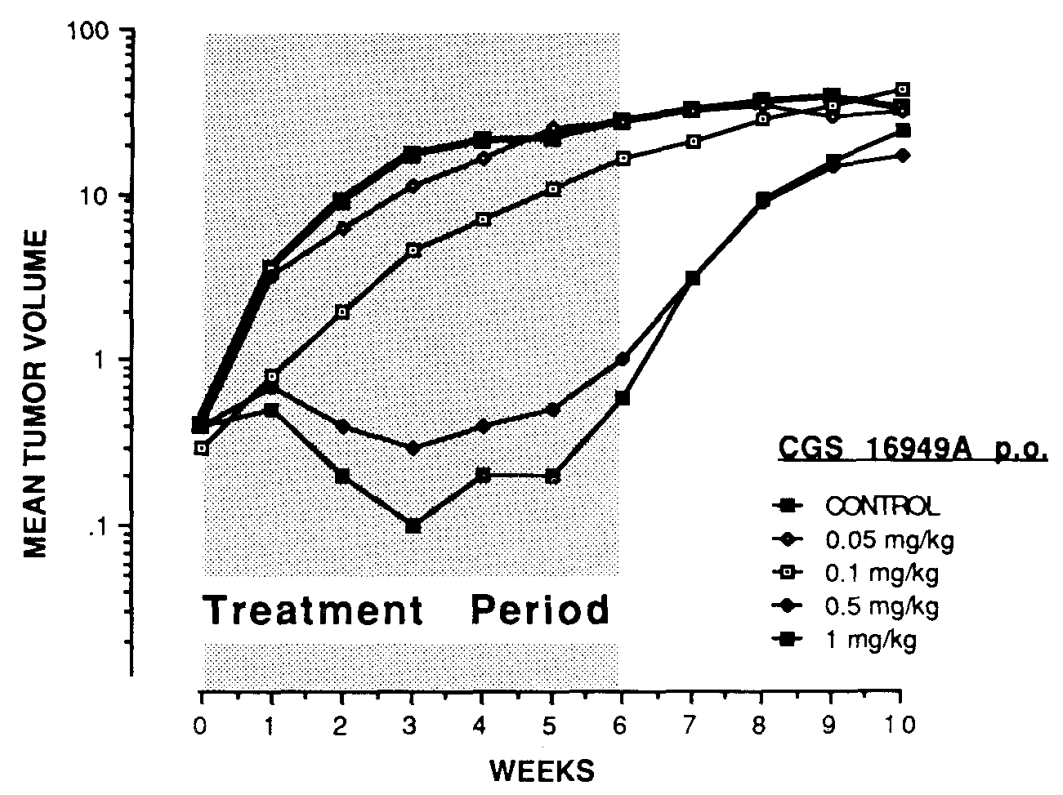

Figure 7. Effect of oral administration of CGS 16949A on mean tumour volume of DMBA-induced mammary tumours in adult female rats; redrawn from data reported in Schieweck et al. 1988; $\mathrm{N}=15$ for each treatment group. 
compare these effects with those of the anti-oestrogen, tamoxifen, in the same model. The results of one such experiment are shown in Figure 8 . Although most of the reported studies with tamoxifen in the DMBA model have administered the compound subcutaneously (e.g. Jordan 1976; Jordan \& Allen 1980), the oral doses of tamoxifen used in our studies were extrapolated from the effective subcutaneous doses and were also comparable to the oral dose administered in one reported study (Fiebig \& Schmähl 1977). It is apparent from the results in Figure 8 that CGS 16949A is far more efficacious than tamoxifen in causing the regression of DMBA-induced mammary tumours.

It appears from Figures 7 and 8 that after three weeks of treatment, mean tumour volume increases. This is due to three of a total of twenty-seven tumours in the $1 \mathrm{mg} / \mathrm{kg}$ group of fifteen animals which grew rapidly and are termed hormoneindependent. After three weeks, as the hormone-dependent tumours become smaller, the three hormone-independent tumours disproportionately contribute to the mean tumour volume. If these three tumours were disregarded in the statistical analysis, mean tumour volume in both the 0.5 and the $1 \mathrm{mg} / \mathrm{kg}$ treatment groups would remain suppressed until the end of treatment. Furthermore, serum oestradiol was significantly suppressed at the end of treatment. Details, including statistical analysis, were reported previously (Schieweck et al. 1988).

During all of the forty-two day treatment schedules used in the anti-tumour studies, CGS 16949A was very well tolerated at doses higher than the maximally effective dose. In contrast, treatment with aminoglutethimide at its maximally tolerated dose was only marginally effective.

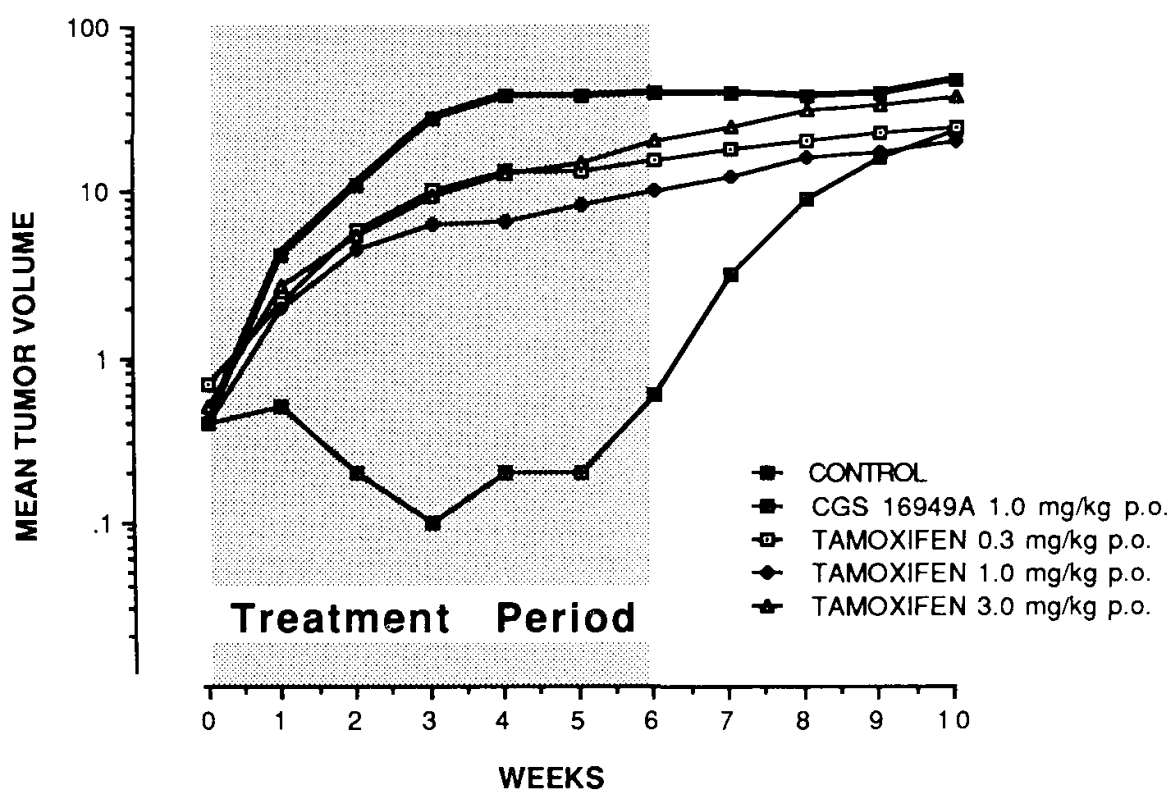

Figure 8. Effects of oral administration of various doses of tamoxifen and a maximal dose of CGS 16949A on mean tumour volume in DMBA-induced mammary tumours in adult female rats; partly redrawn from data reported in Schieweck et al. 1988; $\mathrm{N}=10$ for each treatment group. 


\section{Conclusions}

The results presented above profile CGS $16949 \mathrm{~A}$ as a very potent, non-steroidal competitive inhibitor of the aromatase enzyme system. Both in vitro and in vivo, CGS 16949 A very effectively inhibits the conversion of androgens to oestrogens. In vitro CGS 16949A is very selective in its inhibition of aromatase, only inhibiting other steroidogenic cytochrome P-450-dependent enzymes at concentrations which are orders of magnitude higher than those required for inhibition of aromatase. In vivo, in female rats, this inhibition of oestrogen biosynthesis is manifest in reductions in ovarian oestrogen content and uterine weight, suppression of serum oestradiol and prolactin, an increase in serum luteinising hormone and suppression of the growth of DMBA-induced mammary tumours. The $\mathrm{ED}_{50}$ for most of these effects lie in the range of $0.025-0.1 \mathrm{mg} / \mathrm{kg}$. In this dose range, no adrenal hypertrophy or central nervous system side-effects were observed.

In comparison to aminoglutethimide, CGS $16949 \mathrm{~A}$ is $500-1000$ times as potent in its inhibition of aromatase and far more selective in its action. Inhibition of adrenal steroidogenesis occurs with aminoglutethimide within its therapeutically-effective dose range. With CGS 16949A, there appears to be no inhibition of adrenal steroidogenesis in vivo within its effective dose range. The dissociation of these side effects from the desired therapeutic efficacy distinctly characterises the pharmacological profile of CGS 16949A. Thus CGS 16949A promises to be an effective therapeutic agent for the treatment of oestrogen-dependent diseases, of which one of the most important is oestrogen-dependent breast cancer.

\section{References}

Brodie, A. M. H., Schwarzel, W. C. \& Brodie, H. J. 1976. Studies on the mechanism of estrogen biosynthesis in the rat ovary - I. Journal of Steroid Biochemistry 7, 787-793

-, , Shaikh, A. A. \& Brodie, H. J. 1977. The effect of an aromatase inhibitor, 4-hydroxy-4androstene-3,17-dione, on estrogen-dependent processes in reproduction and breast cancer. Endocrinology 100, 1684-1695

Browne, L. J., Gude, C. \& Steele, R. 1986. 5-(4-Cyanophenyl)-5,6,7,8-tetrahydroimidazol[1,5-a]pyridine. A potent, selective aromatase inhibitor. Abstracts, IX International Symposium on Medicinal Chemistry, Berlin (West), September 14-18, 1986.

Daly, M. J., Jones, G. W., Nicholls, P. J., Smith, H. J., Rowlands, M. G. \& Bunnett, M. A. 1986. Synthesis and biochemical evaluation of analogues of aminoglutethimide based on phenylpyrrolidine-2,5-dione. Journal of Medicinal Chemistry 29, 520-523.

Fiebig, H. H. \& Schmähl, D. 1977. The effect of ovariectomy, tamoxifen and the combination adriamycin and 5-FU on 7,12-dimethylbenz(a)anthracene induced mammary cancer of the rat. Oncology 34, $58-61$.

Grodin, J. M., Siiteri, P. K. \& MacDonald, P. C. 1973. Source of estrogen production in the postmenopausal woman. Journal of Clinical Endocrinology \& Metabolism 36, 207-214.

Hartmann, R. W. \& Batzl, C. 1986. Aromatase inhibitors. Synthesis and evaluation of mammary tumor inhibiting activity of 3-alkylated 3-(4-aminophenyl)piperidine-2,6-diones. Journal of Medicinal Chemistry 29, 1362-1369.

Häusler, A., Schenkel, L., Krähenbühl, C., Monnet, G. \& Bhatnagar, A. S. 1989. An in vitro method to determine the selective inhibition of estrogen biosynthesis by aromatase inhibitors. Journal of Steroid Biochemistry (in press).

Henderson, D., Norbisrath, G. \& Kerb, U. 1986. 1-Methyl-1,4-androstadiene-3,17-dione (SH 489): Characterization of an irreversible inhibitor of estrogen biosynthesis. Journal of Steroid Biochemistry 24, 303-306.

Johnston, J. O. \& Metcalf, B. W. 1984. Aromatase. A target enzyme in breast cancer. In Novel Approaches to Cancer Chemotherapy, ed. Sunkara, P. S., pp. 307-328. Orlando: Academic Press.

Jordan, V. C. 1976. Antiestrogenic and antitumor properties of tamoxifen in laboratory animals. Cancer Treatment Reports 60, 1409-1419. 
- \& Allen, K. E. 1980. Evaluation of the antitumour activity of the non-steroidal antioestrogen monohydroxytamoxifen in the DMBA-induced rat mammary carcinoma model. European Journal of Cancer 16, 239-251.

Knudsen, J. F. \& Mahesh, V. B. 1975. Initiation of precocious sexual maturation in the immature rat treated with dehydroepiandrosterone. Endocrinology 97, 458-468.

Saffran, M. \& Schally, A. V. 1955. In vitro bioassay of corticotrophin: modification and statistical treatment. Endocrinology 56, 523-532.

Schieweck, K., Bhatnagar, A. S. \& Matter, A. 1988. CGS 16949A, a new nonsteroidal aromatase inhibitor: effects on hormone-dependent and -independent tumors in vivo. Cancer Research 48, 834-838.

Schwarzel, W. C., Kruggel, W. G. \& Brodie, H. J. 1973. Studies on the mechanism of estrogen biosynthesis. VIII. The development of inhibitors of the enzyme system in human placenta. Endocrinology 92, 866-880.

Siiteri, P. K. \& Thompson, E. A. 1975. Studies of human placental aromatase. Journal of Steroid Biochemistry 6, 317-322.

Steele, R. E., Mellor, L. B., Sawyer, W. K., Wasvary, J. M. \& Browne, L. J. 1987. In vitro and in vivo studies demonstrating potent and selective estrogen inhibition with the nonsteroidal aromatase inhibitor CGS 16949A. Steroids 50/1-3, 147-161.

Thompson, E. A. \& Siiteri, P. K. 1974. The involvement of human placental microsomal cytochrome P450 in aromatization. Journal of Biological Chemistry 249, 5373-5378. 